\title{
Elementos para la despolitización del cáncer de mama
}

\author{
Elements for depolitization of breast cancer
}

Ana Porroche-Escudero

Recibido: 16/09/2019

Aceptado: 11/12/2019

\section{RESUMEN}

El cáncer de mama ha cobrado una visibilidad sin precedentes en el Estado español. Tras unos orígenes preocupados por el carácter opresivo del rol de la paciente y los determinantes sociales de la incidencia del cáncer, las últimas tres décadas se han caracterizado por una preocupación con el diagnóstico temprano de la enfermedad a través de programas de cribado y de campañas solidarias de concienciación. A priori parece que habría que festejar esta politización progresiva del cáncer de mama que lo ha puesto en la agenda nacional. En este articulo argumento que lo político ha entrado en crisis, despolitizando la enfermedad sin tan apenas levantar sospechas entre los sectores más críticos del país, incluido el feminista. Retomo la crítica de la 'sobreinvisibilización' del cáncer de mama de la antropóloga vasca Mari Luz Esteban (2017) para demostrar cómo nos encontramos en una situación en la que la premisa 'el fin justifica los medios' ha colonizado el pensamiento colectivo. Esta colonización limita la capacidad de las instituciones, personas, organizaciones, profesionales y corporaciones de hacer autocrítica. No planteamos cuestiones entorno a qué temas se abordan, cómo se habla de la enfermedad, cómo se representa a las mujeres y qué temas permanecen silenciados o tabú. Para ilustrar la despolitización presentaré ejemplos de los dos elementos que componen la sobreinvisibilización: los discursos y prácticas sobre el cáncer de mama hipervisibles y aquellos que son invisibilizados. Los primeros son dominantes, monotemáticos y perpetúan mensajes androcéntricos. Los invisibilizados raramente llegan al ámbito público, principalmente porque cuestionan el estatus quo de la industria del cáncer.

Palabras clave: feminismo, cáncer de mama, salud de las mujeres, empoderamiento.

Ana Porroche-Escudero es Doctora en Antropología (U. Sussex, U.K. y Investigadora Senior en Division of Health Research de la Universidad de Lancaster (U.K.). Correo electrónico: a.porrocheescudero@lancaster.ac.uk. ID: https:/ / orcid.org/0000-0002-2740-5273

Cómo citar este artículo: Porroche Escudero, Ana (2019). Elementos para la despolitización del cáncer de mama. Atlánticas. Revista Internacional de Estudios Feministas, 4 (1), 151-178 doi: http: / / dx.doi.org/10.17979/ arief.2019.4.1.5733 


\begin{abstract}
Breast cancer has acquired unprecedented visibility in Spain. Although the origins of the breast cancer movement were concerned with the oppressive patient role and the increasing incidence of the disease, the last three decades have been marked by a focus on diagnosis through screening and awareness campaigns. Some would say that we need to celebrate this progressive politization of breast cancer that has placed the disease on the national agenda. However, I argue that its political purpose is in crisis and has depolitised the disease without raising any suspicions among the most critical sectors, including feminist circles. Building on my work on breast cancer from the past 14 years, in this article I take a cue from Mari Luz Esteban's (2017) critique of the 'overinvisibilization' of breast cancer to demonstrate how it has been depoliticized. I will reinterrogate how breast cancer is spoken about, how women are represented, what topics make headlines and which ones are silenced or remain taboo. In particular,I will illustrate how the 'overinvisibilization' of breast cancer results in various forms of discourses and practices. These include the hypervisibility of hegemonic and monothematic messages that are compounded with sexism; and the invisibilization of those differential experiences and discourses about the disease that questions the status quo of the industry of cancer.
\end{abstract}

Keywords: feminism, breast cancer, women's health, empowerment. 


\section{INTRODUCCIÓN}

El cáncer de mama ha cobrado una visibilidad sin precedentes en occidente, y no menos en el Estado español. Tras unos orígenes preocupados por el carácter opresivo del rol de la paciente y los determinantes sociales de la incidencia del cáncer, las últimas tres décadas se han caracterizado por una preocupación hacia el diagnóstico temprano de la enfermedad a través de programas de cribado y de campañas solidarias de concienciación. A priori parece que habría que festejar esta politización progresiva del cáncer de mama que lo ha puesto en la agenda nacional. Pero pensar en lo político implica también una revisión de la '(sobre)invisibilización' de la enfermedad. La antropóloga Mari Luz Esteban toma de Nicole-Claude Mathieu el concepto de 'sobreinvisibilización' para explicar magistralmente la visibilidad inusitada, compleja y controvertida de esta enfermedad:

Hoy día habría una clara tensión entre, por un lado, la hipervisibilidad de este cáncer en relación a otros, mediante publicaciones, webs, cursos, campañas, etc. que sustentan un modelo positivista y androcéntrico que infantiliza y obliga a las mujeres a feminizarse en una dirección muy concreta: un modelo promovido por la biomedicina, instituciones públicas y privadas y los medios de comunicación; y, por otro lado, el silenciamiento de todas aquellas actitudes y experiencias de mujeres afectadas que no responden a este modelo, o que incluso van claramente en contra del mismo. Podríamos hablar, por tanto, de sobreinvisibilización, puesto que la hipertrofia vigente produce ocultamiento tanto del debate científico y la complejidad de la enfermedad, como de la experiencia y agencia diversa, múltiple y rebelde de las mujeres. Invisibilidad, asimismo, no lo olvidemos, dentro del feminismo (Esteban, 2017, p. 14).

En este artículo sintetizo algunas conclusiones a las que he llegado en los últimos años al reflexionar sobre lo político en el cáncer de mama. Basado en el trabajo de Esteban (2017) utilizo el concepto de sobreinvisibilización para demostrar cómo lo político ha entrado en crisis, despolitizando la enfermedad sin tan apenas levantar sospechas entre los sectores más críticos del país, incluido el feminista. Nos encontramos en una situación en la que la premisa 'el fin justifica los medios' ha colonizado el pensamiento colectivo, atrapándonos en la idea de que la sobreinvisibilización es intrínsecamente positiva puesto que como diría la activista Barbara Brenner "todo el mundo ha oído hablar del cáncer de mama, a menos que vivan en una roca" (Brenner 
2016: 233). Esta colonización limita la capacidad de las instituciones, personas, organizaciones, profesionales y corporaciones de hacer autocritica. No planteamos cuestiones entorno a qué temas se abordan, cómo se habla de la enfermedad, cómo se representa a las mujeres y qué temas permanecen silenciados o tabú.

Para ilustrar la despolitización presentaré ejemplos de los dos elementos que componen la sobreinvisbilización: los discursos y prácticas sobre el cáncer de mama hipervisibles y aquellos que son invisibilizados. Los primeros no solo son dominantes sino que suelen ser estrictamente 'monovocales' (Sandell, 2008) o monotemáticos perpetuando así mensajes androcéntricos. En cambio, los invisibilizados son aquellos que raramente llegan al ámbito público, principalmente porque cuestionan el estatus quo de la industria del cáncer

Este artículo es el resultado de catorce años de investigación sobre el cáncer de mama. Aquí incluyo hallazgos y conclusiones de mis trabajos de master y de doctorado desarrollados en la Universidad de York (2005-2006) y en la Universidad de Sussex (2006-2012), respectivamente; y la revisión sistemática de materiales producidos por la Asociación Española contra el Cáncer como las 7 campañas de concienciación y otros materiales divulgativos disponibles en el portal web de la AECC (2009- 2014). Mi análisis también está influido por mi colaboración con grupos profesionales y activistas como el Breast Cancer Consortium, la Red de Mujeres Profesionales de la Salud (RedCaps), la Plataforma NoGracias, Oncopoeticas, Oncogrrls, Marimachos Cancerosas o la Beca Barbara Rosenblum de Sociologists for Women in Society. Las conversaciones informales a lo largo de los años con compañeras, profesionales de la salud, blogueras y personas afectadas por la experiencia del cáncer, así como con el público en general, han sido una fuente inagotable para esta reflexión. 


\section{UNA NOTA SOBRE EL CONTEXTO QUE PROPICIÓ EL MOVIMIENTO ANTI-CÁNCER}

Dada la escasez de estudios sobre este tema específico en el Estado español es necesario condensar el contexto histórico norteamericano en esta sección. Este repaso es importante por dos motivos. Primero, porque ha ejercido una gran influencia en la historia y estructura del movimiento español. Segundo, porque nos aporta pistas clave para analizar cómo el movimiento anticáncer ha pasado de la politización a la despolitización actual.

En Estados Unidos y en Canadá se han realizado numerosas investigaciones feministas sobre la historia del movimiento anticáncer de mama y los intereses morales, políticos y económicos de que lo apoyan (Brenner, 2000; Elliott, 2007; Goldenberg, 2010; Hodge Mccoid, 2004; Kasper \& Ferguson, 2000; Kaufert, 1996; King, 2001, 2006, 2010; Klawiter, 2008; Lerner, 2001, 2003; Ley, 2009; G. A. Sulik, 2012; Yadlon, 1997; Zavestoski, McCormick, \& Brown, 2004; Zavestoski et al., 2004; Zones, 2000). Aquí sintetizo los puntos más relevantes para comprender la situación actual.

En la década de los 70 un tema que concentraba el interés del movimiento de mujeres era el del empoderamiento a través de la información crítica y la promoción de la autonomía personal. Para responder a estas necesidades el Colectivo de Boston publicó el libro Our bodies, Ourselves (OBOS) en 1971. OBOS fue un libro revolucionario por tres motivos. Uno, fue publicado por mujeres y para mujeres. Dos, fue el primer recurso al que las mujeres podían acudir para acceder a información médica relevante para su salud escrita de manera clara, accesible y basada en la evidencia científica actualizada. Por supuesto, OBOS estaba libre de sesgos de género. Tres, reconocía y valoraba la experiencia y saberes de las mujeres sobre sus cuerpos y procesos de sanación y curación. A finales de los 70 Leonor Taboada dio a conocer OBOS en el Estado español a través de su libro Cuaderno feminista. Introducción al Self-Help (1978), un clásico del feminismo en habla hispana. Este libro nació de la necesidad de transnacionalizar la conciencia política sobre la colonización androcéntrica del 
cuerpo de la mujer, reflejando semejanzas en la mentalidad androcéntrica médica en ambos países.

En Estados Unidos OBOS se convirtió en un éxito de ventas en tiempo récord, inspirando a las mujeres diagnosticadas con la enfermedad a crear de grupos de autoayuda. No es de extrañar que OBOS sirviese como catalizador para el movimiento anticáncer de mama. Una radiografía de la época demuestra que el contexto social no era nada favorable para las mujeres con este tipo de cáncer. En primer lugar, se había disparado la incidencia (número de casos nuevos registrados) y mortalidad. Pocas personas y profesionales se habían planteado que podría ser una epidemia social y medioambiental (Carson, 1962). Además, las mujeres sufrían fuertes presiones sociales y médicas para ocultar los síntomas y secuelas de los tratamientos (Broom, 2001; Epstein, 1986; Wilkinson, 2001). La enfermedad estaba doblemente estigmatizada, dando lugar a situaciones de aislamiento, lástima y repudio. Por un lado, el cáncer se asociaba con la muerte. Algunas personas incluso creían que era contagioso o un castigo divino (Aronowitz, 2001). Por otro lado, se suponía que los tratamientos eran una mutilación de la feminidad (Lorde, 1992). En Diarios de cáncer la poeta norteamericana Audre Lorde explica lucidamente la tiranía del pacto de silencio derivada del doble estigma de la enfermedad. En uno de los pasajes explica la furia y malestar que le causó una enfermera cuando le "dijo que yo le hacía mal a la moral del consultorio porque no usaba prótesis" (Ibid: 27). Para la enfermera la mastectomía era una amenaza ya que funcionaba como un recordatorio de la mortalidad y de la pérdida de la feminidad. La década de los 70 también se caracterizaba por el autoritarismo médico caracterizado por cuatro factores. Relaciones de poder entre profesionales de la salud y las pacientes. Lenguaje científico-técnico era inaccesible. La medicina se convierte en jueza dictando que comportamientos son normales, estableciendo prescripciones médicas y suprimiendo la oportunidad de plantear preguntas. No se cuestionaba la eficacia y necesidad de llevar a cabo procedimientos invasivos de forma rutinaria. Mucho menos se prestaba atención al bienestar integral de la persona enferma (Sumalla, Castejón, Ochoa, \& Blanco, 2013, pp. 8-9). 
Con el paso de los años, la organización colectiva de las mujeres consiguió politizar el cáncer y lograr éxitos. Por ejemplo, se reconoció la enfermedad como un problema de salud pública; se invirtió en la universalización del cribado y en la investigación sobre tratamientos; se crearon grupos de apoyo para las personas enfermas y sus familiares; se desarrolló un tejido social para concienciar a la sociedad sobre el cáncer, informar a las pacientes sobre sus derechos y subvertir las jerarquías médicas y las normas opresivas de género. Un gran éxito fue la promoción de cirugías mamarias menos agresivas siempre que fuesen medicamente posibles. Desde el siglo XIX se practicaba de manera rutinaria la mastectomía radical de Hasteld amparada en la creencia de que 'cuanto más, mejor' (Lerner 2001). Tal fuerte era la creencia que algunos cirujanos realizaron operaciones extensas que eran dolorosas, debilitantes y mutiladoras, de forma innecesaria. En esta cirugía se extirpaba la mama, los músculos pectorales y las cadenas de ganglios debajo de la clavícula y los ganglios linfáticos mamarios internos que están debajo del esternón. Para acceder a estos ganglios había que levantar varias costillas y abrir el esternón un cincel. "La caja torácica de la mujer quedaba gravemente afectada creando una gran concavidad en el centro del pecho. Si la cirugía se practicaba en el lado izquierdo, el corazón quedaba cubierto apenas por una delgada capa de piel" (Ibid, p.81, traducción propia). Mujeres enfermas críticas con el trato biomédico denunciaron que el cuerpo no es un objeto para la experimentación científica y que sus pechos no son prescindibles y sacrificables una vez que las mujeres han cumplido con la función de lactancia (Ibid, p.88-89).

Para resumir y simplificar el proceso complejo de formación del movimiento anticáncer que duró más de tres décadas, se podría decir que se expandió tanto que surgieron diferencias ideológicas irreconciliables dando lugar a escisiones en los años 90 (Klawiter, 2008; Ley, 2009). Basándome en el artículo de Zavestoki et al. (2004) a continuación expongo a grandes rasgos los dos movimientos principales que surgieron.

El movimiento del lazo rosa se convirtió en el modelo dominante en Estados Unidos. Estaba influido estructural y sistemáticamente por el sistema 
biomédico debido a que estaba financiado por la industria del cáncer. ${ }^{1}$ Este modelo tiene varios problemas fundamentales. Uno, como he argumentado en otros trabajos (Porroche-Escudero, 2014, 2016), favorece el paradigma epidemiológico basado en una idea de empoderamiento distorsionada ya que al individualizar la experiencia de la enfermedad (Inhorn \& Whittle, 2001; Lock \& Nguyen, 2010) se centra en educar a las mujeres para que cumplan con las recomendaciones médicas que supuestamente previenen y curan el cáncer. Estas recomendaciones se basan en el cambio del estilo de vida, destacando el énfasis en la dieta baja en grasas, el incremento en la actividad física, el tabaquismo, el consumo de alcohol y la participación en los programas de cribado de mama. Dos, con frecuencia recurre a los estereotipos de género como mujeres hiperfemeninas o al arquetipo esposa-madre para generar miedo y sentimientos de culpa entre las mujeres y así convencerlas de que acaten las normas. Para la socióloga Gayle Sulik (2012) la cultura del lazo rosa se ha reinventado para el consumo en masa. Además depende de la publicidad, la recaudación de fondos y la influencia política y empresarial para mantener el estatus de causa social "más importante" (G. A. Sulik, 2012; G. Sulik \& Zierkiewicz, 2014). Para favorecer el consumismo la mercadotecnia se caracteriza por la "cursilería rosa" infantilizadora y un eslogan en torno a la supervivencia que desprecia la muerte mientras que exige alegría, sentimentalismo y auto-transformación (Ehrenreich, 2001; G. A. Sulik, 2012).

De la escisión también surgió el movimiento medioambiental. Este se oponía a la sexualización creciente de la enfermedad. Rechazaba la asociación indiscutible entre la mastectomía y la mutilación de la feminidad. Quizás, la diferencia más radical, y más en línea con los principios de OBOS, fue la crítica al paradigma epidemiológico en tanto que culpabilizaba a las mujeres de su situación como enfermas. El movimiento medioambiental va a enfatizar el rol de los factores estructurales que impactan en la incidencia y experiencia de la enfermedad para atajar de raíz con la epidemia del cáncer de mama. Así, va a

\footnotetext{
'Tomo prestado el concepto de la 'industria del cáncer' de la socióloga Gayle Sulik (2011:12). La “industria del cáncer se refiere a la industrial multibillonaria compuesta por la industria farmacéutica, el sistema médico, las corporaciones que manufacturan tecnología, las organizaciones de cáncer de mama y las empresas patrocinadoras" (traducción propia). El trabajo brillante de Rosa Medina-Doménech (1996) sobre los orígenes de la radioterapia Española en el primer tercio del siglo XX permite obtener una idea de las motivaciones y funcionamiento de la parte de la industria del cáncer.
} 
abogar por campañas de concienciación sobre las condiciones medioambientales y laborales asociadas con el incremento de la enfermedad instando a la sociedad a demandar macropolíticas saludables (Ley, 2009).

A continuación presento ejemplos concretos de cómo la cultura del lazo rosa actual -basada en el modelo epidemiológico - ha sido despolitizada al contribuir a la sobreinvisibilización del cáncer. Curiosamente, esta sobreinvisiblización es contraria a los principios que guiaron el nacimiento del movimiento anticáncer. De hecho, es el resultado directo de la combinación del modelo epidemiológico y "los principios del cálculo económico de tipo mercantil" (Laval 2012 en Novoa 2016).

\section{LA HIPERVISIBILIZACIÓN DEL CÁNCER DE MAMA}

La hipervisibilización hace referencia a discursos y prácticas ubicuas sobre la enfermedad. Estas no solamente dominan las arenas públicas y biomédicas sino que, como dice Sandell (2008), son 'monovocales' o monotemáticos al centrarse estrictamente en determinados mensajes que son claramente androcéntricos.

\subsection{Sexualización de las mujeres}

La sexualización de la enfermedad y la cosificación de los pechos como objetos de placer sexual masculino son dos formas omnipresentes de hipervisibilización. Durante décadas, críticas feministas han denunciado que este tipo de cáncer ha conseguido atraer la atención pública simplemente porque es una 'enfermedad sexy'. Es una enfermedad que vende. La industria del cáncer representa y escudriña los pechos y cuerpos de las mujeres de una manera casi pornográfica. Con frecuencia las imágenes exhiben cuerpos desnudos que evocan el arquetipo de mujer ideal caracterizado por la delgadez, hiperfeminidad, heterosexualidad, juventud, salud, alegría y simetría corporal. Dos ejemplos que todavía me siguen impactando por la violencia visual y la falta de auto-crítica provienen de las campañas de Ausonia y CoppaFeel!. Vale la pena escribir íntegramente como se publicitaron. 
“Lolita Flores, Olivia Molina, María de Castro, José Toledo y Almudena Cid se desnudan por una buena causa. Más sensuales que nunca, las famosas españolas han sido retratadas por el fotógrafo Alfonso Ohnur con una lazo rosa y un pañuelo a la cabeza como madrinas de la nueva campaña contra el cáncer de mama de Ausonia" (Mujerhoy, 2010).

“El cáncer de pecho es sexy. ¿No crees? Es más sexy que el cáncer testicular...Si no nos crees pregúntale a Mel B quien se ha fotografiado en topless para apoyarnos en el mes de octubre" (HuffPost UK, 2012).

Estas campañas no constituyen actos reivindicativos para reclamar la diversidad corporal de las mujeres y despatologizar los cuerpos asimétricos, sin pechos o mastectomizados. Todo lo contrario. Los pechos se muestran como objetos donde el placer (del otro) y el consumo van a la par (Porroche-Escudero, 2015b). La imagen de CoppaFeel! para la revista Cosmopolitan ilustra perfectamente la preocupación por satisfacer el placer masculino. Mel B es la protagonista de la campaña. Posa con el torso desnudo en un primer plano. Detrás aparece su marido en aquella época, Jorgie Porter. Él coge los pechos de ella para ocultarlos de la mirada del espectador. La mirada impenetrable de Porter y la naturaleza del acto posesivo de tomar los pechos como quien toma un objeto envía el mensaje de que los pechos de Mel B no son suyos, sino de él. Para el resto de las mujeres también envía el mensaje de que los pechos son el único atributo que nos hace deseables para los hombres, por lo tanto tenemos que hacer todo lo posible para preservar nuestra feminidad. Se supone que la auto-exploración mamaria es el vehículo para detectar el cáncer y así incrementar las posibilidades de evitar una mastectomía y preservar la feminidad.

Este discurso monovocal tan extendido, raramente conceptualiza los pechos como un órgano importante para la propia mujer en su vertiente estética, encarnada o sexual, que las prótesis y cirugía no pueden imitar (PorrocheEscudero, 2013). Para Audre Lorde (1992), la obligatoriedad de los pañuelos, el

2 Pongo en cursiva la palabra obligatoriedad para enfatizar la cualidad de obligatorio de estos artefactos debido a presiones sociales y médicas. Al poner el énfasis en las presiones sociales mi intención no es 
maquillaje, las prótesis y las reconstrucciones mamarias son artefactos al servicio del patriarcado.

\subsection{Frivolidad}

En las últimas décadas se ha presentado el cáncer de mama de forma contradictoria y problemática. Por un lado, se ha medicalizado el riesgo a desarrollar la enfermedad. Como resultado los pechos se representan como bombas de relojería a las que hay temer y vigilar de cerca - incluso extirpar sin ser medicamente necesario. Por otro lado, el cáncer de mama y las acciones de concienciación se presentan como algo divertido y festivo. No solo transmiten un mensaje que suaviza la crueldad de la enfermedad, sino que ignoran la letalidad de algunos tipos de tumores (independientemente de cuando los diagnostiquen). La campaña de CoppaFeel! ilustra la frivolización de la experiencia de enfrentarse a un cáncer. Con referencia a la exploración mamaria Jorgie Porter dijo lo siguiente:

Soy un hombre de tetas así que no he tenido ningún problema posando para la foto o ayudando a mi esposa a explorarse los pechos. ¿A que hombre no le gustaría hacerlo? Es algo divertido y muy importante (HuffPost UK, 2012).

Para muchas mujeres la auto-exploración y otras medidas de detección, como por ejemplo la mamografía de cribado, no son divertidas porque causan incertidumbre, miedo y preocupación. La campaña de Pancreatic Cáncer Action del año 2014 “Ojalá tuviese un cáncer de mama” es otro ejemplo que frivoliza la enfermedad, reforzando a su vez el mensaje de que el cáncer de mama no es tan serio como otros tumores.

La manera en la que se frivoliza el cáncer no debería sorprendernos. La historiadora Grazia de Michele (2016) nos recuerda que los orígenes del lazo rosa no son precisamente filantrópicos. La compañía de cosméticos Esteé Lauder comenzó a utilizar el color rosa como estrategia de marketing tras

juzgar la decisión individual de las personas que toman la decisión de utilizar estos artefactos. Como he dicho en múltiples ocasiones, cada una gestiona la enfermedad como mejor puede y cree conveniente. 
realizar grupos de discusión con consumidoras. El objetivo de los grupos de discusión fue averiguar qué color que resultaba 'reconfortante y femenino' para apelar a las masas. Así, el color rosa fue seleccionado. Feministas como Barbara Ehrenreich (Ehrenreich, 2001) argumentan que la edulcoración que rodea a este tipo de color rosa en la industria del cáncer actúa como una 'anestesia'. Es decir, suaviza la crueldad de la enfermedad y niega la mortalidad.

\subsection{El síndrome de la súper paciente}

El comic autobiográfico y de Bessie et al. (2017) pone de relieve la hipervisibilidad del ideal de paciente perfecto que está fuertemente arraigado en nuestra sociedad, afectando a millones personas en las diferentes fases de la enfermedad: diagnóstico, tratamiento, supervivencia, recidiva (la recurrencia del cáncer), y enfermedad avanzada. Desafortunadamente es muy difícil alcanzar este ideal basado en el control de la enfermedad a través de la disciplina corporal (mediante dietas estrictas y ejercicio físico) y emocional (manteniendo una actitud positiva).

Las campañas educativas, publicitarias y expresiones familiares del tipo "tu vida está en tus manos", "una vida más sana puede ayudarte" o "ante un cáncer lo más importante es la actitud positiva" transmiten la creencia de que el auto-control personal puede prevenir el cáncer y las recidivas. Un aspecto cruel de estos mensajes es que infiere que las personas enfermas (aquellas que son diagnosticadas con cáncer, se encuentran mal, experimentan efectos secundarios o mueren) son malas pacientes porque no se esforzaron lo suficiente para recuperar la salud. Desgraciadamente los santos remedios no existen y las personas a nivel individual pueden hacer poco o nada para prevenir el cáncer. Retomaré este punto más adelante.

Para Gayle Sulik, autora del best seller Pink ribbon blues: How breast cáncer culture undermines women's health (2012), la retórica de la paciente perfecta reproduce y enmascara estereotipos de género opresivos. De las mujeres enfermas o supervivientes se espera que se comporten como súper-mujeres: combinando la alegría y el pensamiento positivo con una actitud jovial, servicial y sexy. Según 
este modelo, las mujeres enfermas tienen que ser madres, hijas y vecinas ejemplares que sirven como inspiración para otras mujeres. De ellas se espera la 'sonrisa brava' o lo que Audre Lorde llamaba el pacto de silencio. Una función principal de la sonrisa brava es proteger a los demás, en particular a la familia y amistades, de la incomodidad de los efectos secundarios y el miedo de ver a una madre/esposa/amiga enferma que puede morir. Cuatro décadas más tarde del nacimiento del movimiento anti-cáncer todavía persiste la expectativa de la sonrisa brava en el Estado español. Ainhoa Irueta (2017, p. 189) lo describe elocuentemente en su Autobiografía de una marimacho cancerosa:

Muchas mujeres afectadas me decían que aparentaban "normalidad" y trataban de ocultar su dolor porque no querían que nadie sufriera por su culpa. ¡Ser para los demás!

Tal y como se puede observar, la hipervisibilización a través de la frivolidad, la sexualización y el ideal de la paciente perfecta ha tenido el efecto contrario a la politización del cáncer de mama ya que refuerza tabúes sobre la mortalidad y estereotipos de género sobre la perdida de la feminidad que el movimiento anticáncer trataba de erradicar.

\section{INVISIBILIZACIÓN}

En esta sección presento algunas narrativas que son invisibles porque raramente llegan al ámbito público y político, principalmente porque cuestionan los sesgos y motivaciones de la industria del cáncer.

\subsection{Falta de información sobre la prevención primaria}

Hay que aplaudir los esfuerzos para invertir en detección precoz y tratamientos, dos aspectos importantes en el proceso terapéutico. De hecho, la mejoría de los tratamientos explica la reducción de la mortalidad en las últimas décadas y la disminución de los efectos secundarios de algunos fármacos e intervenciones. Pero hay dos preguntas que están ausentes de los debates 
políticos y públicos: ¿por qué aumentan los casos de cáncer? (Vandenberg, 2019) y si el cáncer no fuese una epidemia ¿a dónde se destinarían los recursos?

Si no hubiese cáncer miles de cientos de personas no tendrían que pasar por el mal trago del diagnóstico, los tratamientos, las secuelas y, en muchos casos, la muerte. Al mismo tiempo el dinero que se invierte en programas de detección precoz y tratamientos podría invertirse en mujeres con otros problemas de salud más urgentes. Por ejemplo, la persistencia de las enfermedades cardiovasculares y la diabetes está relacionada con los recortes en los servicios públicos y el deterioro de las condiciones laborales y sociales. La verdadera "madre del cordero" de la incidencia no es solamente el envejecimiento de la población, sino los determinantes sociales de la contaminación medioambiental ligada al cáncer y los conflictos de interés de la industria del cáncer ${ }^{3}$ (Forcades i Vila, 2017); que como dice la endocrinóloga feminista Carme Valls (2017, p. 85), está más interesada en tratar que en prevenir.

Paradójicamente, el mensaje de la lucha contra la epidemia del cáncer es el que mueve a millones de personas y euros todos los años. Por lucha se sobreentiende prevención. Sin embargo, la mayoría de los esfuerzos se centran en concienciar a la población sobre la importancia del cáncer; investigar para mejorar los tratamientos de tumores ${ }^{4}$ en fase 1 y 2 y en la detección precoz (o prevención secundaria). Para acabar con una epidemia hay que erradicar las causas de la epidemia (prevención primaria). La prevención secundaria (diagnóstico precoz) y los tratamientos no previenen que el cáncer aparezca en el cuerpo. Como mucho, lo detectan y lo intentan curar.

Desafortunadamente se estima que entre el 60-92\% de los cánceres están causados por la exposición creciente a sustancias tóxicas en el agua, la comida, el aire, así como en nuestro entorno laboral. Sin embargo, menos de un 10\% del

\footnotetext{
3 Sobre los conflictos de interés de la industria del cáncer recomiendo el artículo de Teresa Forcades i Vila (2017) que se puede descargar en la página web de la revista MyS. Mujeres y Salud. https:/ / matriz.net/numeros.htm. El blog de la Plataforma NoGracias también tiene numerosas entradas incisivas y escritas de forma accesible sobre este tema: http://www.nogracias.eu/tag/conflictos-deinteres/

${ }^{4}$ Las investigaciones sobre las metástasis, el tipo de tumor que mata, recibe escasa financiación tanto desde el ámbito público como privado.
} 
dinero recaudado a través de patrocinios, mercadotecnia rosa y actividades solidarias va destinado a investigar y regular el uso de los productos asociados a procesos cancerígenos (Lynn, 2007; Valls-Llobet et al., 2017). Investigadoras de la Universidad de Stirling ha llevado a cabo numerosos estudios sobre salud laboral y cáncer y han concluido que esta paradoja (donde se habla de prevención del cáncer pero la mayoría de las acciones van a diagnosticarlo o tratarlo) es "un desastre injusto de salud pública", que con voluntad política podría prevenir dolor y sufrimiento innecesario (O'Neill \& Qasrawi, 2007). Esta situación todavía es más trágica si se tiene en cuenta que desde el campo de la salud pública se ha demostrado que las intervenciones destinadas a promover avances legales y a implementar macropolíticas saludables tienen el mayor grado de impacto positivo en los determinantes sociales del cáncer (Whitehead, 2007). Además, el énfasis en prevenir el cáncer a través de la modificación de los estilos de vida individuales es problemático.

\subsection{Desigualdades sociales y cáncer}

Las desigualdades sociales en el cáncer es un problema gravísimo pero invisibilizado. Tras revisar la literatura sobre desigualdad social y cáncer, Samuel Arias (Arias, 2009, p. 341) concluyó que los grupos socio-económicos más vulnerables no "solo tienen más probabilidades de desarrollar la enfermedad (incidencia), morir más pronto y sufrirla sin la oportunidad de cuidado paliativo". Los escasos debates sobre desigualdades sociales y cáncer se suelen centrar en el acceso a los métodos diagnósticos y a los tratamientos de calidad. Pero hay otros aspectos de igual relevancia.

Incidencia. He explicado que una parte importante de la evidencia científica apunta a las condiciones en que las personas nacen, viven y trabajan como la causa estructural del cáncer. Las sustancias tóxicas están en los productos más insospechados, mucho de los cuales se suponen saludables y seguros como los vegetales y el ganado del que nos alimentamos, los productos de limpieza y las mascotas que nos acompañan (Davis, 2004; Engel, Rasanayagam, Gray, \& Rizzo, 2018; Jacobs \& Dinham, 2003; Valls-Llobet, 2006, 2010) Sin embargo, el cáncer de mama tradicionalmente se ha representado como una enfermedad 
causada por los estilos de vida irresponsables (p. ej., poco ejercicio, dieta rica en grasas, pensamiento negativo, fumar, beber, etc.) (Yadlon, 1997). Según esta lógica, las mujeres podrían prevenir y curar el cáncer con una información y una educación adecuadas para que modifiquen su comportamiento (PorrocheEscudero, 2014, 2016). Pero hay tres "peros" a esta lógica.

1. Con demasiada frecuencia las personas tienen poca información y poder para controlar la exposición a agentes cancerígenos en su entorno laboral y social. La revisión sistemática de Engel et al. (2018a; 2018b) sobre Trabajo y cáncer de mama femenino desde 2002-2017 concluye que el riesgo de cáncer de mama aumenta con las exposiciones derivadas de los turnos de noche, los químicos (por ejemplo en la agricultura, la industria de manufacturación de plásticos y envasadoras de alimentos) y el estrés laboral. ${ }^{5}$ Cuando las sustancias químicas alteran el equilibrio hormonal aumenta el riesgo de desarrollar cáncer. Estas sustancias se llaman disruptores endocrinos. ${ }^{6}$ El estrés crónico a su vez puede alterar las biologías locales de las personas (Brunner, 1997) tales como la expresión genética o el sistema inmune, dando lugar a procesos de inflamación celular que favorecen la división celular, incrementando el riesgo del cáncer. El estrés crónico se produce cuando se dan situaciones estructurales de pobreza, falta de poder, de capital, experiencias traumáticas desde la infancia. El estrés socio-laboral y la exposición a

\footnotetext{
${ }^{5}$ Vale la pena mencionar que la relación entre el estrés social y laboral y el cáncer está siendo estudiada desde hace años aunque no es un área de investigación favorecida. Esta falta de atención se debe en parte a los conflictos de interés de la industria del cáncer más interesada en tratar que en prevenir, y en las corporaciones patrocinadoras más interesadas en los beneficios que en la salud pública. El apasionado libro de Devra Davis (2004) When smoke ran like water: Tales of environmental deception and the battle against pollution explica de forma brillante cómo la contaminación medioambiental afecta la salud y las estratagemas de las grandes corporaciones para censurar la evidencia científica que las delata. La organización norteamericana Breast Cancer Action ha denunciado durante décadas la hipocresía de algunas corporaciones patrocinadoras ya que producen productos que contienen sustancias cancerígenas. Véase https://www.thinkbeforeyoupink.org/

${ }^{6}$ Dolores Romano Mozo (Romano Mozo, 2012, p. 14) define los disruptores endocrinos como las "sustancias químicas capaces de alterar el equilibrio hormonal y la regulación del desarrollo embrionario y, por tanto, con capacidad de provocar efectos adversos sobre la salud de un organismo o de su progenie".
} 
sustancias químicas asociadas al cáncer está directamente relacionado con el nivel socio-económico de las personas. Así los roles de género, el nivel económico y la etnia, incrementa las probabilidades de que las mujeres pertenecientes a ciertos grupos desarrollen trabajos caracterizados por las exposiciones a substancias toxicas y precariedad laboral que da lugar al estrés (Johnson, 2011), incrementando las probabilidades de desarrollar cáncer.

2. La focalización en los estilos de vida individualiza y privatiza los problemas sociales que incrementan el riesgo de cáncer de mama. Desgranemos un ejemplo típico de estos mensajes. El Instituto Catalán de Oncología recomienda 10 consejos para "prevenir el cáncer en tu día a día" (Costas-Caudet, 2015): 1. Sigue una alimentación variada y sana. 2. Practica el ejercicio físico cada día. 3. Vacúnate y vacuna a tus hijos. 4. Hazte las pruebas de detección precoz del cáncer. 5. Si eres mujer y puedes, intenta dar el pecho a tus hijos para reducir el riesgo cáncer. 6. Evita el tabaco. 7. Limita el consumo de alcohol. 8. Evita el exceso de peso. 9 Protégete del sol. 10. Protégete en el trabajo de cualquier sustancia nociva. Otros profesionales hablan de protegerse descansando diariamente. Aunque no pongo en duda que estos consejos pueden ayudar a llevar una vida saludable y minimizar los efectos secundarios de algunos tratamientos, pecan de esconder un mensaje neoliberal, clasista y sexista donde la salud no es un derecho sino un privilegio que se compra con dinero.

¿Cuántas familias pueden permitirse el lujo de comprar comida variada y saludable? ¡Si hasta los embutidos de pueblo y las conservas llevan sustancias químicas nocivas y es dificilísimo encontrar tiendas para comprar legumbres y especias a granel o productos cosméticos libres de tóxicos! En lugar de culpabilizar a las mujeres ¿por qué no se regula la industria ganadera, agrícola y alimenticia para prohibir el uso de sustancias químicas nocivas en los alimentos de consumo animal y humano? De esta manera todas las personas podrían acceder de forma rutinaria a alimentos saludables en todos los establecimientos. 
¿Cuántas mujeres cuidadoras pueden descansar todas las noches ajenas a las presiones económicas de no poder llegar a final de mes? ¿Cuántas personas no tienen ni la energía ni el tiempo para "cuidarse a sí mismas" ni "hacer ejercicio" porque dividen su tiempo entre los cuidados y las largas jornadas laborales? En lugar de culpabilizar a las mujeres ¿por qué no se diseñan políticas para mejorar las condicionales laborales y el estado de bienestar para quitar responsabilidades y estrés? (Escribà-Agüir \& Fons-Martinez, 2014).

¿Cuántas personas enfermas no pueden dedicarse a recuperarse de la enfermedad porque tienen que reincorporarse al mercado de trabajo a pesar de los efectos secundarios debilitantes de los tratamientos?

¿Cuántas personas están expuestas a la contaminación del aire cuando salen a pasear o a trabajar, y cuántas evitan salir al exterior para protegerse sin ser conscientes de que la contaminación penetra en el interior de nuestros refugios alcanzando niveles de concentración más altos que en el exterior? (Hill 2018; McArthur 2019).

¿Cuántas personas pueden protegerse realmente en su trabajo de las substancias cancerígenas, y cuántas pueden denunciar, compartir su historia públicamente o pedir "por escrito en el servicio de prevención de riesgos laborales si tu empresa utiliza algún agente cancerígeno y cuáles son las medidas que puedes tomar" (Alguacil, 2015)? Para las personas en situaciones laborales vulnerables estas opciones no son opciones reales si quieren mantener el empleo. Para proteger a las personas trabajadoras sería más efectivo endurecer las políticas laborales para que se eliminen las exposiciones a substancias cancerígenas. Además, se debería exigir mayor responsabilidad a las corporaciones y empresas a la hora de informar a su plantilla y de proveer el material de protección adecuado, así como denunciar casos de malas prácticas. 
3. Desde hace años se observa un gradiente social relacionado con en el consumo de tabaco, alcohol, el sobrepeso y la falta de ejercicio a lo largo de todo el espectro de la población (desde las personas más ricas hasta las más pobres), pero las personas más pobres tienen las tasas más altas. Raramente se explica que este tipo de comportamiento, que a priori parece poco razonable, puede ser un mecanismo racional para sobrellevar las situaciones de estrés. Es decir el tabaco, el alcohol y la comida pueden funcionar como "vías de escape" cuando las personas tienen poco control sobre sus vidas. ¿Cuáles son las consecuencias de prohibir o desaprobar estos comportamientos sin proponer medidas complementarias para mejorar las causas del estrés social y laboral que fomentan los hábitos perjudiciales? Uno, se estigmatiza a los grupos de mujeres que no pueden cumplir con las recomendaciones médicas. Dos, aumenta el riesgo de estrés ya que las personas no pueden recurrir a sus vías de afrontamiento tradicionales para aliviar el sufrimiento relacionado con las situaciones socio-laborales difíciles. No solo eso, el estrés da lugar a sentimientos de culpa y a la sustitución de unos comportamientos perjudiciales por otros. En este contexto sería necesario combinar intervenciones educativas sobre los estilos de vida y con acciones que actúen sobre los determinantes sociales de la salud que son el origen y causa del problema en primer lugar.

La calidad de vida durante la enfermedad. Con frecuencia se habla de supervivencia como si la supervivencia fuese solo una cuestión de vivir más años. Pocas veces se habla de calidad de vida y mucho menos se habla de bienestar económico. Para muchas mujeres que están en fase de tratamiento y para las que han superado la enfermedad el cáncer de mama puede desencadenar la pobreza. Los tratamientos pueden ser debilitantes, impactando en el empleo. En la actualidad las personas enfermas cuentan con pocos derechos socio-legales para estar enfermas. Si además tienen unas condiciones laborales precarias es difícil que puedan dedicar el tiempo suficiente para recuperarse ya que el parón laboral puede amenazar la economía y el puesto de trabajo. En miles de casos las pacientes oncológicas que se siente enfermas o tienen un alto riesgo de recaída (recidiva) reciben el alta, "porque según el sistema médico, están listas 
para reanudar su vida laboral" (Porroche-Escudero \& Figueroa, 2016). Si la persona deja voluntariamente su trabajo porque no puede realizarlo no tiene derecho a percibir el paro.

Esta situación de desamparo, denunciada por la activista Beatriz Figueroa desde hace años, se debe a la falta de voluntad política de aquellos agentes e instituciones que se supone que son responsables de velar por la salud. El sistema biomédico no reconoce el carácter debilitante de algunas secuelas, negándose a certificar medicamente el sufrimiento de las personas. El mercado laboral discrimina a las personas enfermas al despedir, no renovar contratos o dificultar la integración en el puesto de trabajo. El sistema de bienestar social y de pensiones pone numerosas trabas adicionales para que las mujeres no puedan obtener el certificado de incapacidad y/o discapacidad. Por ejemplo, Figueroa tuvo que acudir a los tribunales en tres ocasiones para solicitar que se le reconociese la incapacidad. Su solicitud fue rechazada dos veces. Le dijeron que "no había signos de discapacidad" o que era "apta para trabajar en otros puestos de trabajo". También llegaron a decir que "su familia podía apoyarle". Esta última respuesta se basa en la visión (hetero)normativa de que las mujeres están casadas, por supuesto con un hombre que además es el cabeza de familia. También presupone que todas las mujeres tienen una familia que puede proporcionarles apoyo económico. Sin embargo, Beatriz que está soltera y que perdió a sus padres hace años sólo puede contar con el apoyo del "sistema", y este le está fallando (Porroche-Escudero, 2015a).

Para concluir, creo que es importante visibilizar cómo la precariedad económica de las personas enfermas impacta en la salud. Sinceramente espero que estos ejemplos evoquen en la lectora imágenes y sentimientos que desestabilicen la idea romántica de que la supervivencia es un camino de rosas:

- Disminuye la participación social y el ocio, lo cual a su vez reduce los contactos sociales y las relaciones personales. Se sabe que los contactos sociales son agentes protectores de la salud. 
- Favorece la dependencia, ya que las personas tienen que hacer elecciones para ahorrar en la compra, el transporte, el alquiler o las facturas.

- Reduce la salud física. Por ejemplo, la falta de dinero reduce las oportunidades de ocio que a su vez limita la movilidad física e incrementa la morbilidad; los tratamientos complementarios, tan necesarios para el bienestar de las personas afectadas, son prohibitivos; y algunas personas escatiman la ingesta de medicinas para ahorrar.

- Restringe las posibilidades de formación profesional, que a su vez reduce las posibilidades de incorporarse al mercado laboral.

- Deteriora la salud psicológica, ya que la pobreza puede causar estrés, angustia y depresión. Ya he mencionado antes que la pobreza puede afectar profundamente la biología y algunas investigaciones sugieren que puede incrementar el riesgo de cáncer.

\section{A MODO DE CONCLUSIÓN}

Este articulo nace con el ánimo de estimular discusión colectiva sobre lo político en el cáncer de mama. Me baso en el concepto de 'sobreinvisibilización' que Mari Luz Esteban (2017) toma de Nicole-Claude Mathieu para analizar algunos ejemplos de prácticas y discursos que han dado lugar a la despolitización de la enfermedad. Distinguir entre la sobreinvisibilización y la visibilización es fundamental. La sobreinvisibilización se rige por intereses puramente biomédicos y económicos. Así enfatiza o invisibiliza determinados tipos de información guiada no por los intereses de las personas enfermas, sino por criterios de maximización de beneficios. La visibilización por el contrario es un acto político. Muestra la realidad y la multiplicidad de experiencias de estar enferma. Desarticula la idea de que todo vale en el nombre de la concienciación sobre el cáncer de mama. Analiza los discursos y las prácticas de los profesionales, organizaciones e instituciones vinculadas al cáncer de mama para

\footnotetext{
- Agradezco a Marta Maella por sus conversaciones sobre el impacto económico de los tratamientos complementarios pero necesarios para la sanación.
} 
determinar qué intereses hay detrás de cada uno de ellas y cuáles son las consecuencias.

He comenzado el articulo con un recorrido histórico de los orígenes feministas del movimiento anti-cáncer de mama en los años 70. Este recorrido es necesario para poner de manifiesto cómo el movimiento anticáncer ha pasado de la politización a la despolitización actual. Después he presentado ejemplos de los dos elementos que componen la sobreinvisbilización: los discursos y prácticas sobre el cáncer de mama hipervisibles y aquellos que son invisibilizados. Los primeros no solo son dominantes sino que suelen ser estrictamente 'monovocales' (Sandell, 2008) o monotemáticos perpetuando así mensajes androcéntricos. Por ejemplo, abundan los mensajes que frivolizan y sexualizan la enfermedad presentándola como algo benigno o como una oportunidad para agradar sexualmente a la mirada del otro. La auto-exploración y las campañas de educación y detección precoz se presentan como algo divertido y digno de celebrar. La hipervisibilización también juega con el ideal de mujer-paciente perfecta siempre al servicio de los demás y dispuesta a acatar con las recomendaciones biomédicas sin plantear preguntas. Más allá de conseguir que gran parte de la población sea consciente de la importancia del cáncer la hipervisibilización no ha conseguido avanzar los principios asociados al movimiento feminista de los años 70. Al contrario, la cultura rosa se ha convertido en uno de los instrumentos más efectivos de la cultura patriarcal a la hora de perpetuar representaciones idealizadas de los cuerpos de mujeres y de los roles de géneros basadas en la sumisión de las mujeres al mandato biomédico y a la felicidad de sus familias.

La cara oculta de la sobreinvisibilización es la invisibilización de temas de crucial importancia como la prevención primera y las desigualdades de salud en el cáncer. Esta invisibilidad se traduce en una falta de debate público y de políticas destinadas a proteger la salud de las personas. En esta sección he querido enfatizar que la obsesión con modificar los estilos de vida de las mujeres para prevenir el cáncer sin considerar la magnitud de los factores estructurales que posibilitan la contaminación ambiental, el estrés laboral o la falta de apoyos socio-económicos y legales es una manera de deformar la 
comprensión de la prevención primaria, individualizando y privatizando los problemas sociales detrás de la epidemia del cáncer.

\section{AGRADECIMIENTOS}

Me gustaría dar las gracias a mis compañeras y amigas Inma Hurtado y Belén Nogueiras por todos los regalos de tiempo, corrección, ánimos e ideas para mejorar este manuscrito. También quiero agradecer el apoyo intelectual del National Institute for Health Research Collaboration for Leadership in Applied Health Research ad Care North West Coast (NIHR CLAHRC NWC). Las opiniones expresadas no reflejan el criterio de NIHR.

\section{BIBLIOGRAFÍA}

Alguacil, Juan (2015). ¿Trabajar puede provocar cáncer? Retrieved 13 February 2019, from Mejor Sin Cáncer website: https: / / mejorsincancer.org/2015/05 / 14/ trabajar-puede-provocarcancer/

Arias, Samuel A. (2009). Inequidad y cáncer: Una revisión conceptual. Rev. Fac. Nac. Salud Pública, 27(3), 341-348.

Aronowitz, Robert. A. (2001). Do not delay: Breast cancer and time, 1900-1970. Milbank Quarterly, 79(3), 355-386. https://doi.org/10.1111/14680009.00212

Bessie, Adam; Sulik, Gayle \& Parenteau, Marc (2017). The perfect cancer patient. Retrieved from https://narratively.com/im-not-the-perfect-cancersurvivor-but-ive-learned-to-live-with-that/

Boston Women's Health Book Collective (1971). Our bodies, ourselves: A book by and for women. New York: Simon and Schuster.

Brenner, Barbara (2000). Sister support: Women create a breast cancer movement. In Anne Kasper \& Susan J. Ferguson (Series Ed.), Breast cancer: Society shapes an epidemic (pp. 325-354). New York: St. Martin's Press.

Broom, Dorothy (2001). Reading breast cancer: Reflections on a dangerous intersection. Health:, 5(2), 249-268. https: / / doi.org/10.1177/136345930100500206 
Brunner, Eric (1997). Socioeconomic determinants of health: Stress and the biology of inequality. BMJ, 314(7092), 1472. https: / / doi.org/10.1136/bmj.314.7092.1472

Carson, Rachel (1962). Silent Spring. Boston: Houghton Mifflin.

Costas-Caudet, Laura (2015). 10 consejos para prevenir el cáncer en tu día a día-Mejor Sin Cáncer. Retrieved 12 February 2019, from Mejorsincaner.org website: https: / / mejorsincancer.org/2015/04/15/10-consejos-para-prevenir-elcancer-en-tu-dia-a-dia/

Davis, Devra L. (2004). When smoke ran like water: Tales of environmental deception and the battle against pollution. New York, NY: Basic Books.

De Michele, Grazia (2016). Radical objects: 'Cancer sucks'. History Workshop Online. Retrieved from http://www.historyworkshop.org.uk/radicalobjects-cancer-sucks /

Ehrenreich, Barbara (2001). Welcome to cancerland. Retrieved 26 August 2013, from Harper's Magazine website: http: / / harpers.org/archive/2001/11/ welcome-to-cancerland /

Elliott, Charlene (2007). Pink!: Community, contestation, and the colour of breast cancer. Canadian Journal of Communication, 32(3). Retrieved from http: / / cjc-online.ca/index.php/journal / article/view / 1762

Engel, Connie L.; Rasanayagam, Sharima M.; Gray, Janet M. \& Rizzo, Jeanne (2018). Work and Female Breast Cancer: The State of the Evidence, 2002-2017. New Solutions: A Journal of Environmental and Occupational Health Policy, 28(1), 55-78.

Epstein, Julia J. (1986). Writing the unspeakable: Fanny Burney's mastectomy and the fictive body. Representations, 16, 131-166.

Escribà-Agüir, Vicenta \& Fons-Martinez, Jaime (2014). Crisis económica y condiciones de empleo: Diferencias de género y respuesta de las políticas sociales de empleo. Informe SESPAS 2014. Gaceta Sanitaria, 28, 37-43. https: / / doi.org/10.1016/j.gaceta.2014.01.013

Esteban, Mari Luz (2017). Prólogo. Cáncer de mama: La rebelión feminista no ha hecho más que empezar. In Cicatrices (invisibles). Perspectivas feministas sobre el cáncer de mama (pp. 13-20). Barcelona: Bellaterra.

Forcades i Vila, Teresa (2017). Cáncer y negocio: Consideraciones éticas. MyS. Mujeres y Salud, (42), 32-34.

Goldenberg, Maya (2010). Working for the cure: Challenging pink ribbon activism. In Roma Harris, Nadine Wathen, \& Sally Wyatt (Series Ed.), Configuring Health Consumers: Health Work and the Imperative of Personal Responsibility (pp. 140-159).

Hill, Sharon (2018). Study breast cancer cases at bridge, says customs union and researcher I Windsor Star. Windsor Star (Canada). Retrieved from 
https: / / windsorstar.com/news / local-news / investigate-breast-cancercases-at-ambassador-bridge-says-customs-union-and-researcher

Hodge Mccoid, Cathy (2004). Why is prevention not the focus for breast cancer policy in the United States rather than high-tech medical solutions. In Arachu Castro \& Merril Singer (Eds.), Unhealthy health policy (pp. 351362). New York: Oxford AltaMira Press.

HuffPost UK. (2012). Mel B reveals cancer scare as she goes topless for breast cancer charity Coppafeel. Retrieved 13 February 2019, from HuffPost UK website: https: / / www.huffingtonpost.co.uk/2012/09/12/mel-bcancer-scare-cosmopolitan_n_1876592.html

Inhorn, Maracia C. \& Whittle, K. Lisa. (2001). Feminism meets the "new" epidemiologies: Toward an appraisal of antifeminist biases in epidemiological research on women's health. Social Science $\mathcal{E}$ Medicine, 53(5), 553-567.

Irueta, Ainhoa (2017). Autobiografía de una marimacho cancerosa. In Porroche Escudero, Ana; Coll-Planas, Gerard \& Caterina Ribas (Eds.), Cicatrices (in)visibles. Perspectivas feministas sobre el cáncer de mama (pp. 181-190). Barcelona: Bellaterra.

Jacobs, Miriam \& Dinham, Barbara. (2003). Silent invaders: Pesticides, livelihoods, and women's health. London; New York; New York: Zed Books in association with Pesticide Action Network UK; Distributed in the USA exclusively by Palgrave.

Johnson, Robin E. (2011). Cancer disparities: An environmental justice issue for policy makers. Environmental Health Policy. Physicians for Social Responsibility. Psr.org.

Kasper, Anne S. \& Ferguson, Susan. J. (Eds.). (2000). Breast Cancer: Society Shapes an Epidemic. New York: St. Martin's Press.

Kaufert, Patricia (1996). Women and the debate over mammography: An economic, political and moral history. In Carolyn Sargent \& Caroline Brettel (Eds.), Gender and Health: An International Perspective (pp. 167186). New Jersey: Prentice-Hall.

King, Samantha (2001). Marketing Generosity: Avon's Women's Health Programs and New Trends in Global Community Relations. (Research Paper). International Journal of Sports Marketing E Sponsorship, 3(3), 267.

King, Samantha (2006). Pink ribbons, Inc. Breast cancer and the politics of philanthropy. Retrieved from http://www.upress.umn.edu/bookdivision/books/pink-ribbons-inc

King, Samantha (2010). Pink diplomacy: On the uses and abuses of breast cancer awareness. Health Communication, 25(3), 286-289. https: / / doi.org / 10.1080/10410231003698960

Klawiter, Maren (2008). The biopolitics of breast cancer: Changing cultures of disease and activism. Minneapolis: University of Minnesota Press. 
Lerner, Barron H. (2001). The breast cancer wars: Hope, fear, and the pursuit of a cure in twentieth-century America. New York: Oxford University Press.

Lerner, Barron H. (2003). 'To see today with the eyes of tomorrow': A history of screening mammography. Canadian Bulletin of Medical History/Bulletin Canadien d'histoire de La Médecine, 20(1), 299-321.

Ley, Barbara L. (2009). From pink to green disease prevention and the environmental breast cancer movement. New Brunswick, N.J.: Rutgers University Press.

Lock, Margaret \& Nguyen, Vinh-Nguyen. (2010). An Anthropology of Biomedicine. Chichester, West Sussex: Wiley-Blackwell.

Lorde, Audre (1992). The cancer journals. San Francisco: Aunt Lute Books.

Lynn, Helen (2007). Politics and Prevention: Linking breast cancer and our environment. Utrecht: : Women in Europe for a Common Future.

McArthur, Jane E. (2014). The Toronto Star and the politics of breast cancer (MA, University of Windsor). Retrieved from https: / / scholar.uwindsor.ca/ etd/5033

McArthur, Jane E. (2019). As the oceans rise, so do your risks of breast cancer. Retrieved 12 February 2019, from The Conversation website: http: / / theconversation.com/ as-the-oceans-rise-so-do-your-risks-ofbreast-cancer-108420

Mujerhoy (2010). Por segundo año consecutivo, Ausonia y la Asociación Española Contra el Cáncer ponen en marcha una nueva campaña contra el cáncer de mama de Ausonia. Retrieved 13 February 2019, from Mujerhoy website: https: / / www.mujerhoy.com

O’Neill, Rory \& Qasrawi, Jawad. (2007). Hazards work cancer prevention kit. Retrieved from Stirling University's Occupational and Environmental Health and Safety Research Group website: http: / / www.hazards.org/cancer/preventionkit/index.htm

Porroche-Escudero, Ana (2013). Luces y sombras de la reconstrucción mamaria. MyS. Mujeres y Salud, 34-35, 30-33.

Porroche-Escudero, Ana (2014). Perilous equations? Empowerment and the pedagogy of fear in breast cancer awareness campaigns. Women's Studies International Forum, 47, Part A, 77-92. https: / / doi.org/10.1016/j.wsif.2014.08.003

Porroche-Escudero, Ana (2015a). Beatriz Figueroa: Relinking cancer treatments, incapacity to work, the social security system, and patients economic rights. Breast Cancer Consortium Quarterly, 4. Retrieved from http: / / breastcancerconsortium.net/beatriz-figueroa-relinking-cancertreatments-incapacity-work-social-security-system-patients-economicrights /

Porroche-Escudero, Ana (2015b). La violencia de la cultura rosa. Las campañas de concienciación de cáncer de mama. 37, 32-35. 
Porroche-Escudero, Ana (2016). Empoderamiento: El Santo Grial de las campañas de salud pública sobre el cáncer de mama. Revista Internacional de Sociología, 74(2), e031.

Porroche-Escudero, Ana \& Figueroa, Beatriz. (2016). Drets econòmics de les persones afectades de càncer. In Porroche-Escudero, Ana; Coll-Planas, Gerard \& Caterina Ribas (Eds.), Cicatrius (in)visibles Perspectives feministes sobre el càncer de mama (pp. 175-186). Barcelona: Bellaterra.

Romano Mozo, Dolores (2012). Disruptores endocrinos Nuevas respuestas para nuevos retos. Instituto Sindical de Trabajo, Ambiente y Salud (ISTA).

Sandell, Kerstin (2008). Stories without significance in the discourse of breast reconstruction. Science, Technology $\mathcal{E}$ Human Values. https: / / doi.org/10.1177/0162243907306693

Sulik, Gayle (2012). Pink ribbon blues: How breast cancer culture undermines women's health. New York; Oxford: Oxford University Press.

Sulik, Gayle \& Zierkiewicz, Edyta (2014). Gender, power, and feminisms in breast cancer advocacy: Lessons from the United States and Poland. Journal of Gender and Power, 1(1), 111-145.

Sumalla, Eric. C.; Castejón, Vanessa; Ochoa, Cristian \& Blanco, Ignacio. (2013). ¿Por qué las mujeres con cáncer de mama deben estar guapas y los hombres con cáncer de próstata pueden ir sin afeitar? Oncología, disidencia y cultura hegemónica. Psicooncología, 10(0), 7-56.

Taboada, Leonor (1978). Cuaderno feminista. Introducción al Self- Help. Barcelona: Fontanella.

Valls-Llobet, Carme (2006). Factores de riesgo para el cáncer de mama. MyS. Mujeres y Salud, 18, 16-20.

Valls-Llobet, Carme (2010). Contaminación ambiental y salud de las mujeres. Investigaciones Feministas, 1(0), 149-159. https: / / doi.org/-

Valls-Llobet, Carme (2017). Influencia de la salud laboral y el medio ambiente en el cáncer de mama. In Cicatrices (in)visibles. Perspectivas feministas sobre el cáncer de mama (pp. 83-92). Barcelona: Bellaterra.

Vandenberg, Laura N. (2019, February 7). It's time to talk about cancer prevention-EHN. Retrieved 12 February 2019, from Environmental Health News website: https://www.ehn.org/laura-n-vandenberg-itstime-to-talk-about-cancer-prevention-2628192178.html

Whitehead, Margaret (2007). A typology of actions to tackle social inequalities in health. Journal of Epidemiology and Community Health, 61(6), 473-478.

Wilkinson, Sue (2001). Breast cancer: Feminism, representations and resistance - a commentary on Dorothy Broom's 'Reading breast cancer'. Health:, 5(2), 269-277. 
Yadlon, Susan (1997). Skinny women and good mothers: The rhetoric of risk, control, and culpability in the production of knowledge about breast cancer. Feminist Studies, 23(3), 645-677.

Zavestoski, Stephen; McCormick, Sabrina \& Brown, Phil (2004). Gender, embodiment, and disease: Environmental breast cancer activists' challenges to science, the biomedical model, and policy. Science as Culture, 13(4), 563-586.

Zones, Jane S. (2000). Profits from pain: The political economy of breast cancer. In Susan J. Ferguson \& Anne S. Kasper (Eds.), Breast cancer: Society shapes an epidemic (pp. 119-151). New York: St. Martin's Press. 